\title{
Caracterização anatomopatológica e imuno-histoquímica dos tumores das glândulas cutâneas em cães
}

\author{
[Anatomopathological and immunohistochemical characterization of skin gland tumors in dogs] \\ J.S. Vasconcelos ${ }^{1}$, R.A.S. Siqueira ${ }^{1}$, R.B. Lucena ${ }^{2}$ A.F.M. Dantas $^{3}$, A.G.A. Alves ${ }^{4}$ \\ ${ }^{1}$ Aluno de pós-graduação - Universidade Federal de Campina Grande - Patos, PB \\ ${ }^{2}$ Universidade Federal da Paraíba - Areia, PB \\ ${ }^{3}$ Universidade Federal de Campina Grande - Campina Grande, PB \\ ${ }^{4}$ Centro de Ciência Animal e Veterinária - Universidade de Trás-os-Montes e Alto Douro - Vila Real, Portugal
}

\begin{abstract}
RESUMO
O presente estudo objetivou caracterizar os aspectos anatomopatológicos e imuno-histoquímicos dos tumores das glândulas cutâneas em cães. A caracterização morfológica seguiu a classificação atualizada da Organização Mundial de Saúde. Para a caracterização imuno-histoquímica, utilizaram-se anticorpos monoclonais primários anti-citoqueratina 14 (CK14), vimentina, p63, calponina, EGFR e Ki-67. Dos animais examinados, 66,67\% (18/27) eram machos e 33,33\% (9/27) fêmeas, 21 tinham raça definida e seis eram sem raça definida (SRD), com idade variando entre sete e 15 anos. Dos tumores caracterizados, 40,74\% eram hepatoides (11/27), 29,63\% sebáceos (8/27), 25,92\% apócrinos (7/27) e 3,70\% meibômio (1/27). Os tumores malignos representaram $55,56 \%$, e os benignos $44,44 \%$. Com esses resultados, foi possível demonstrar que os tumores das glândulas cutâneas em cães são frequentes, sem predileção por raça, sexo e com idade superior ou igual a sete anos. Os anticorpos CK 14, p63, vimentina e EGFR foram imunoexpressos nas células basais, células de diferenciação sebácea dos tumores hepatoides e de meibômio e células mioepiteliais. Entretanto, a vimentina e o EGFR não demonstraram imunomarcação para os tumores sebáceos. A calponina foi um bom marcador para as células mioepiteliais. O índice de Ki-67 foi mais acentuado nos tumores malignos em relação aos benignos. No entanto, estudos futuros utilizando maior número de casos se fazem necessários.
\end{abstract}

Palavras-chave: cães, tumores cutâneos, análise, imuno-histoquímica, histopatologia

\begin{abstract}
The present study aimed to characterize the anatomopathological and immunohistochemical aspects of cutaneous glandular tumors in dogs. Tumours were diagnosed according to the WHO criteria for canine skin neoplasms. For the immunohistochemical characterization, the primary monoclonal antibodies anticytokeratin 14 (CK14), vimentin, p63, calponin, EGFR and Ki-67 were used. Males were 66.67\% (18/27) and females 33.33\% (9/27), 21 had a defined race and 6 were mixed breed, with ages varying from 7 to 15 years. The tumors characterized were $40.74 \%$ hepatoid (11/27), 29.63\% sebaceous (8/27), $25.92 \%$ apocrine (7/27) and 3.70\% Meibômio (1/27). Malignant tumors accounted for $55.56 \%$ and benign tumors $44.44 \%$. With these results it was possible to demonstrate that tumors of cutaneous glands in dogs are frequent, with no predilection for race, sex and with an age $\geq$ seven years. The CK 14 antibodies, p63, vimentin, and EGFR were imunoexpressed in the basal cells of the sebaceous cell differentiation and Meibomian hepatoides tumors and myoepithelial to cells. However, vimentin and EGFR did not demonstrate immunostaining for sebaceous tumors. Calponin was a good marker for myoepithelial cells. The Ki-67 index was more pronounced in malignant tumors compared to benign tumors. However, more studies are needed mainly using a higher number of tumors.
\end{abstract}

Keywords: dogs, cutaneous tumors, analysis, immunohistochemistry, histopathology

Recebido em 27 de outubro de 2017

Aceito em 3 de maio de 2018

E-mail: veterinariojsv@yahoo.com.br 


\section{INTRODUÇÃO}

Entre as dermatopatias que afetam os cães, os tumores cutâneos foram a segunda patologia mais diagnosticada, após apenas da hipersensibilidade à picada de pulga (Sischo et al., 1989). O crescente aumento dos casos oncológicos em animais de companhia se deve à elevada sobrevida destes, devido a fatores como nutrição adequada, protocolos terapêuticos eficientes, vacinação, além de uma maior dedicação dos proprietários (Withrow e Vail, 2007).

As neoplasias sebáceas ou com diferenciação sebácea são comuns no cão, variando entre $6 \%$ e $21 \%$ dos tumores cutâneos dessa espécie (Goldschmidt e Hendrick, 2002). As neoplasias das glândulas hepatoides (perianais) (sebáceas modificadas) são consideradas as mais comuns nos canídeos (Scott et al., 2001; Gross et al., 2005), constituindo o terceiro tumor cutâneo mais diagnosticado nos machos (Withrow e Vail, 2007). No entanto, os tumores benignos são hormônios (estrogênios e androgênios) dependentes (Petterino et al., 2004), e os carcinomas são hormônios independentes (Scott et al., 2001; Kirpensteijn, 2006). Enquanto as neoplasias das glândulas de meibômio (glândulas sebáceas modificadas) apresentam uma frequência de $10 \%$ das neoplasias das glândulas de origem sebácea, as neoplasias das glândulas apócrinas correspondem de $0,7 \%$ a $2,2 \%$ de todos os tumores de pele de canídeos (Gross et al., 2005).

O diagnóstico histopatológico dos tumores das glândulas cutâneas é realizado com base nas características morfológicas das células neoplásicas, em que se relacionam principalmente suas formas citoplasmáticas e nucleares, além de arranjos e estroma de sustentação (Goldschmidt e Hendrick, 2002). Muitas vezes pode ser difícil definir a origem celular e, consequentemente, o diagnóstico definitivo. Nessa caso, necessita-se da imunohistoquímica para determinar a origem celular dos tumores (Polak e Van Noorden, 2003).

Estudos imuno-histoquímicos utilizando o anticorpo p63 em neoplasias de glândulas cutâneas de cães demonstraram sensibilidade e especificidade para identificação das células basais e mioepiteliais de tumores malignos
(Saraiva et al., 2008). A citoqueratina 14 (CK14) e a vimentina apresentaram imunorreatividade para as células mioepiteliais. A calponina foi testada em glândulas de origem apócrina, mostrando-se reativa para as células mioepiteliais e os miofibroblastos (Saraiva, 2007). Ao avaliar a glândula hepatoide normal, Alves (1999) demonstrou que as citoqueratinas de médio e largo espectro apresentaram reatividade moderada, entretanto a citoqueratina 14 apresentou acentuada reatividade e a vimentina foi negativa para as neoplasias hepatoides. O anticorpo Ki-67 revelou ser um marcador sensível para verificar a proliferação celular.

O diagnóstico das neoplasias de glândulas cutâneas em cães é frequente, entretanto são escassos os estudos imuno-histoquímicos das glândulas cutâneas nesses animais. Diante do exposto, o presente estudo objetivou caracterizar os aspectos anatomopatológicos e imunohistoquímicos dos tumores de glândulas cutâneas em cães.

\section{MATERIAL E MÉTODOS}

Para o estudo, foram utilizadas 27 amostras de tumores de glândulas cutâneas, oriundas de cães atendidos em clínicas veterinárias da região metropolitana de João Pessoa, Paraíba, Brasil, e do arquivo do Laboratório de Histologia e Anatomia Patológica (LHAP) da Universidade de Trás-os-Montes e Alto Douro (UTAD), em Vila Real, Portugal. As fichas que acompanhavam as amostras continham, além do histórico clínico, informações sobre raça, sexo e idade, localização anatômica e características das lesões macroscópicas dos cães.

O processamento e as análises das amostras foram realizados nos laboratórios de Patologia Veterinária (LPV) do Centro de Ciências Agrárias (CCA) da Universidade Federal da Paraíba (UFPB), no Laboratório de Patologia Animal (LPA) do Centro de Saúde e de Tecnologia da Universidade Federal de Campina Grande (UFCG) e no Laboratório de Histologia e de Anatomia Patológica (LHAP) da Universidade de Trás-os-Montes e Alto Douro (UTAD).

As amostras utilizadas para o estudo foram coletadas por biópsias excisionais, 
acondicionadas em solução de formalina tamponada a $10 \%$ e, depois, clivadas. Em seguida, foram processadas rotineiramente, incluídas em blocos de parafina, cortadas em espessura de $3 \mu \mathrm{m}$ para confecção de lâminas e coradas em hematoxilina e eosina. Posteriormente, foi feita a análise utilizando-se microscópio do LHAP Nikon Eclipse E-600, com câmera Nikon DS-12 acoplada, e o software NSI Elements da Nikon.

A caracterização morfológica dos tumores das glândulas cutâneas foi realizada com base na classificação da Organização Mundial de Saúde (OMS) (Goldschmidt et al., 1998). Para caracterização imuno-histoquímica, utilizaram-se secções de tecido de $3 \mu \mathrm{m}$ de espessura em lâminas silanizadas e incubadas com anticorpos monoclonais primários anticitoqueratina 14 (CK14), vimentina, gene p63 (p63), calponina, receptor do fator de crescimento epidérmico (EGFR) e Ki-67 (Tab. 1), empregando-se o sistema de detecção de polímero Novolink Novocastra (Leica Biosystems).

Tabela 1. Relação dos anticorpos e protocolos utilizados na caracterização imuno-histoquímica das neoplasias de glândulas cutâneas em cães

\begin{tabular}{cccccc}
\hline Anticorpo & Clone & Fabricante & $\begin{array}{c}\text { Recuperação } \\
\text { antigênica }\end{array}$ & Diluição & Incubação \\
\hline CK 14 & LL002 & Thermo Scientific & Micro-ondas & $1: 800$ & $\begin{array}{c}\text { Durante a noite; } \\
4^{\circ} \mathrm{C}\end{array}$ \\
Vimentina & $\begin{array}{c}\text { NCL-L-VIM- } \\
\text { V9 }\end{array}$ & Novocastra & Micro-ondas & $1: 100$ & $\begin{array}{c}\text { Durante a noite; } \\
4^{\circ} \mathrm{C}\end{array}$ \\
p63 & 4A4 & Neomarkers & Micro-ondas & $1: 150$ & $\begin{array}{c}\text { Durante a noite; } \\
4^{\circ} \mathrm{C}\end{array}$ \\
EGFR & 31G7 & Zymed Laboratories & Pepsina & $1: 50$ & $\begin{array}{c}\text { Durante a noite; } \\
4^{\circ} \mathrm{C}\end{array}$ \\
Calponina & CALP & DakoCytomation & Micro-ondas & $1: 500$ & $\begin{array}{c}2 \text { horas; } \\
\text { ambiente } \\
2 \text { horas; } \\
\text { Ki-67 }\end{array}$ \\
ambiente
\end{tabular}

*Foi utilizado apenas nas neoplasias das glândulas apócrinas.

A recuperação antigênica dos anticorpos CK14 e vimentina foi realizada com tampão citrato $(\mathrm{pH}$ 6,0 ) em um ciclo de micro-ondas $750 \mathrm{w}$, por sete minutos. A recuperação do p63 foi realizada com tampão citrato ( $\mathrm{pH} 6,0)$ em cinco ciclos de micro-ondas $750 \mathrm{w}$, por cinco minutos. A recuperação da calponina foi realizada com tampão citrato ( $\mathrm{pH}$ 6,0) em três ciclos de microondas $750 \mathrm{w}$, por cinco minutos, com intervalos de dois minutos. A recuperação para o EGFR foi realizada por digestão enzimática $(0,4 \%$ de pepsina) (Dako, Dinamarca) em solução de $\mathrm{HCl}$ $0,01 \mathrm{~N}(\mathrm{pH}=2)$, durante 30 minutos, a $37^{\circ} \mathrm{C}$. Para o Ki-67, a recuperação antigênica foi realizada em tampão citrato (pH 6,0), em panela de pressão, por dois minutos, em alta pressão.

A epiderme adjacente normal foi utilizada como controle positivo para a CK14; para a vimentina, utilizou-se a derme (fibras de colágenos e endotélio de vasos sanguíneos); para o p63, a epiderme e o folículo piloso; para o EGFR, a epiderme; para a calponina, a derme (células mioepiteliais das glândulas apócrinas); e para o Ki-67, a epiderme.

Foram considerados positivos os cortes (amostras) que apresentaram imunomarcação para os anticorpos testados. Considerou-se positiva a imunomarcação citoplasmática para a CK14, a vimentina, o EGFR e a calponina, enquanto no caso do Ki-67 e do p63 a imunomarcação positiva foi nuclear. Para a quantificação da imunorreatividade, utilizou-se a seguinte classificação: leve, moderada e acentuada, consoante a intensidade da imunorreatividade observada. Entretanto, a quantificação da imunorreatividade para o Ki-67 foi realizada de acordo com Pena et al. (1998), em que o índice de proliferação foi obtido contando-se até mil células positivas e negativas de cada caso, em objetiva de 40x. O índice de $1 \%$ a $5 \%$ é considerado leve, $>5 \%$ a $10 \%$ moderado e $>10 \%$ acentuado. 
O presente trabalho foi aprovado pela Comissão de Ética da Universidade Federal da Paraíba, sob o parecer número 054/2015.

\section{RESULTADOS}

Dos 27 cães com nódulos cutâneos, 66,67\% (18/27) eram machos e 33,33\% (9/27) fêmeas. Vinte e um eram de raça definida e seis sem raça definida (SRD); a idade variou de sete a 15 anos, com uma média de 9,8 anos. A raça, o sexo, a idade, a localização anatômica e o diagnóstico morfológico dos cães com tumores das glândulas cutâneas estão distribuídos de acordo com a Tab. 2. As únicas lesões macroscópicas observadas foram nódulos subcutâneos em todos os casos, sendo quatro deles ulcerados $(03,12,18$ e 21$)$. O tamanho dos nódulos variou de 0,3 a $5,0 \mathrm{~cm}$ de diâmetro.

Tabela 2. Relação de sexo, raça, idade, localização anatômica e diagnóstico morfológico de cães com neoplasias de glândulas cutâneas

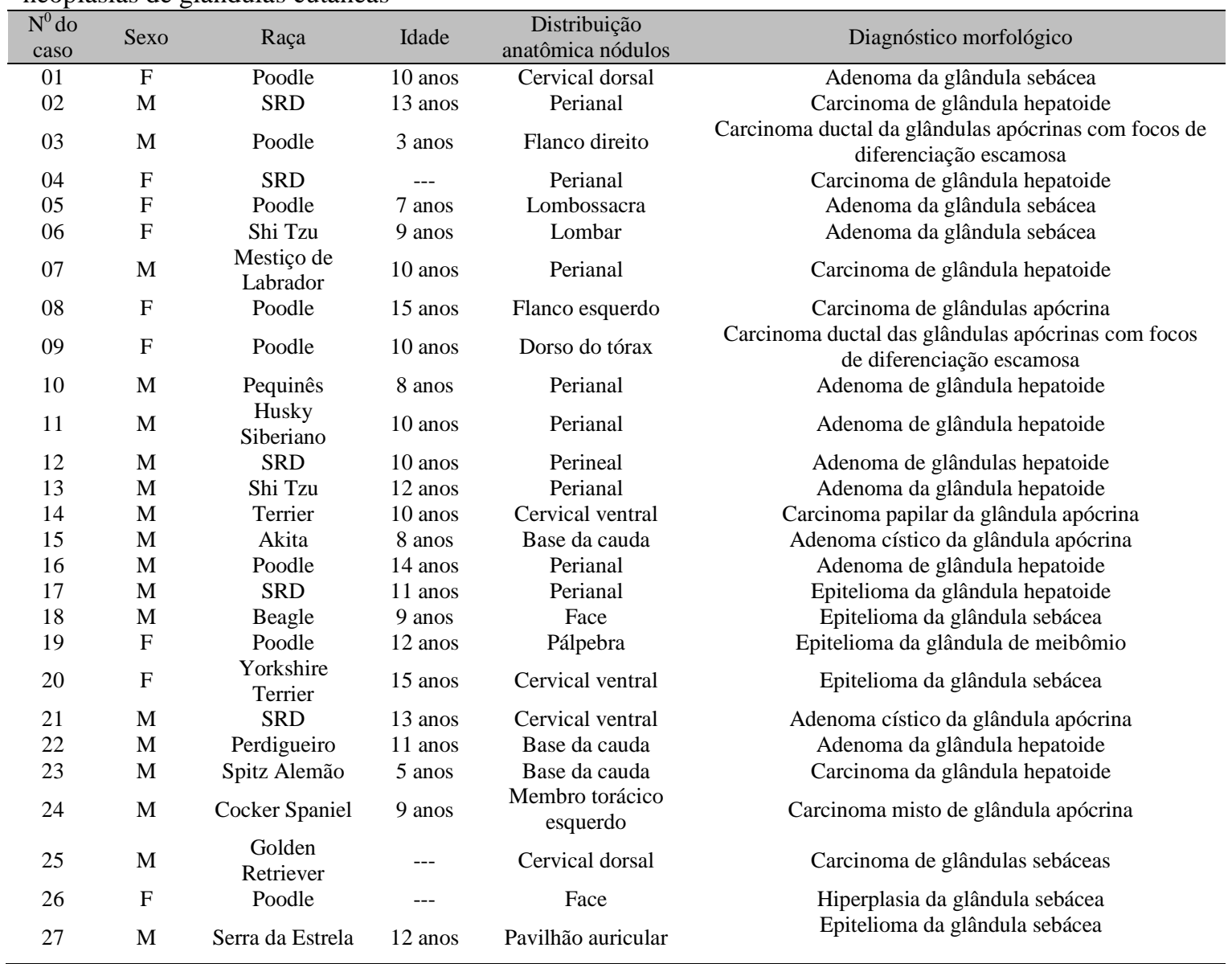

$\mathrm{F}=$ fêmea; $\mathrm{M}=$ macho e $\mathrm{SRD}=$ sem raça definida.

Os tumores das glândulas hepatoides foram os mais frequentes, diagnosticados em 40,74\% (11/27) dos cães acometidos. Nódulos subcutâneos foram as lesões macroscópicas observadas. Em seguida, com 29,63\% (8/27), os tumores das glândulas sebáceas. As principais lesões macroscópicas foram nódulos subcutâneos $(100 \%$ - 8/8), no entanto dois deles encontravam-se ulcerados $(25,00 \%-2 / 8)$. A neoplasia da glândula de meibômio foi observada em 3,70\% (1/27) dos cães e clinicamente o animal apresentava um pequeno nódulo multilobulado na região palpebral. As neoplasias das glândulas sudoríparas apócrinas representaram 25,92\% (7/27) dos casos. A macroscopia foi caracterizada por nódulos subcutâneos $100 \%$ (7/7), entretanto dois deles encontravam-se ulcerados $28,58 \%(2 / 7)$. 


\section{Caracterização anatomopatológica...}

Dos tumores das glândulas hepatoides, 54,55\% (6/11) eram benignos e 45,45\% (5/11), malignos. Entre os tumores das glândulas sebáceas, 50,00\% (4/8) eram benignos e 50,00\% (4/8), malignos. O tumor diagnosticado na glândula de meibômio era maligno. Os tumores benignos e malignos das glândulas sudoríparas apócrinas representaram 28,57\% (2/7) e 71,43\% (5/7), respectivamente (Fig. 1).

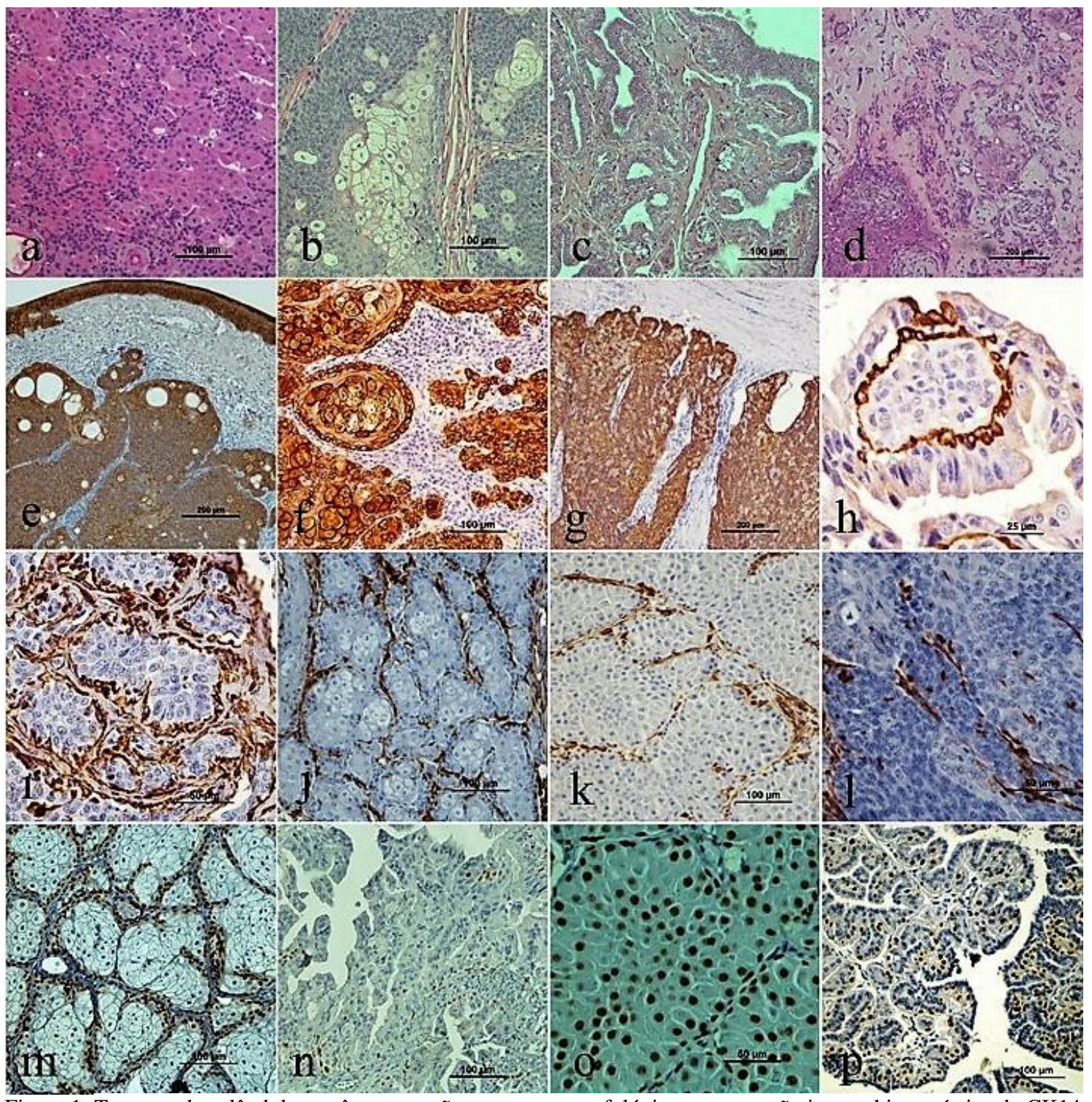

Figura 1. Tumores das glândulas cutâneas em cães: aspectos morfológicos e expressão imuno-histoquímica de CK14, vimentina e p63. a) Carcinoma da glândula hepatoide, HE 20x. Caso 4. b) Epitelioma da glândula sebácea, HE. 20x. Caso 20. c) Carcinoma da glândula apócrina com focos de diferenciação escamosa, HE 20x. Caso 9. d) Carcinoma misto da glândula apócrina, HE 10x. Caso 24. e) Epitelioma da glândula sebácea, positivo para CK14. 10x. Caso 27. f) Adenoma da glândula sebácea, positivo para CK14. Caso 6. g) Carcinoma da glândula hepatoide, positivo para CK14. 10x. Caso 7. h) Carcinoma papilar da glândula apócrina, positivo para CK14. 60x. Caso 14. i) Carcinoma de glândulas apócrina, positivo para vimentina. 40x. j) Adenoma da glândula sebácea, positivo para vimentina. 20x. Caso 6. k) Epitelioma da glândula hepatoide, positivo para vimentina. 20x. Caso 22. 1) Epitelioma da glândula sebácea, positivo para vimentina. 40x. Caso 18. m) Hiperplasia da glândula sebácea, positiva para p63. 20x. Caso 26. n) Carcinoma misto da glândula apócrina, positivo para vimentina. 20x. Caso 24. o) Carcinoma da glândula hepatoide, positivo para p63. 20x. Caso 23. p) Adenoma cístico da glândula sudorípara apócrina, positivo para p63. 20x. Caso 15. 
$\mathrm{Na}$ histologia, os tumores das glândulas hepatoides foram adenomas das glândulas hepatoides, os quais se caracterizaram pela proliferação de células hepatoides bem diferenciadas, exibindo leve pleomorfismo celular e nuclear. As células continham núcleos que variaram de arredondados a ovalados hipercromáticos e citoplasma abundante eosinofílico, arranjadas em ninhos entremeados por moderado estroma fibrovascular. Foi possível observar raras figuras de mitose por campo de grande aumento (objetiva de 40x), epiteliomas das glândulas hepatoides pela proliferação de células basaloides e algumas células com diferenciação hepatoide. As células basaloides de reserva apresentaram elevada atividade mitótica, associada a discreta atipia nuclear. Os carcinomas das glândulas hepatoides caracterizaram-se pela ausência de padrão lobular, no entanto apresentaram invasão periférica. As células basaloides exibiram pleomorfismo nuclear e hipercromatismo. As células que exibiram diferenciação hepatoide possuíam citoplasma vacuolado descorado ou fracamente eosinofílico, pleomorfismo nuclear e nucléolos proeminentes. Figuras de mitose foram encontradas nas células basaloides de reserva e nas células diferenciadas.

Os tumores das glândulas sebáceas foram hiperplasia sebácea e se caracterizaram por serem nódulos bem diferenciados com proliferação de células basaloides de reserva e de células de diferenciação sebáceas sem alterações neoplásicas. Os adenomas sebáceos caracterizaram-se por serem massas intradérmicas bem dermarcadas. Em alguns casos, a massa estendeu-se da interface dermoepidérmica para o subcutâneo, formando lóbulos discretos de vários tamanhos. $\mathrm{Na}$ periferia desses lóbulos, as células basaloides encontravam-se variando o arranjo de uma camada a várias camadas de espessura variável. No interior dos tumores, predominou a presença de sebócitos. Os epiteliomas sebáceos apresentaram células de reservas de citoplasmas escassos e núcleos ovoides hipercromáticos, constituindo massa neoplásica. Os núcleos das células neoplásicas diferenciadas eram grandes e vesiculosos, observando-se até três nucléolos. Também foi possível observar até três mitoses por campo de aumento em objetiva de 40x. Enquanto os carcinomas sebáceos apresentaram células em moderado grau de diferenciação sebácea, formando múltiplos lóbulos, compostos de células tumorais exibindo um grau variável de alterações citoplasmáticas, as células tumorais apresentaram pleomorfismo nuclear, associado a hipercromasia e moderada atividade mitótica. As características histológicas do carcinoma de meibômio são semelhantes aos carcinomas das glândulas sebáceas.

Os tumores das glândulas sudoríparas apócrinas foram adenomas císticos, os quais foram caracterizados por apresentarem lúmen dilatado com secreção, proliferação de células epiteliais cuboides com citoplasma eosinofílico granular abundante e nucléolo localizado basalmente e podendo exibir secreção de decapitação. Os carcinomas das glândulas sudoríparas apócrinas foram tumores bem diferenciados, compostos de células com citoplasma eosinofílico e abundante, núcleo largo e ovoide com nucléolo proeminente. Exibiram leve pleomorfismo nuclear e celular e baixa atividade mitótica. Os carcinomas mistos das glândulas sudoríparas apócrinas foram caracterizados por apresentarem proliferações malignas de células glandulares acompanhadas de proliferação de células mioepiteliais. Também se observaram alterações metaplásicas do mioepitélio para tecidos ósseo e cartilaginoso. Os carcinomas papilares eram bem diferenciados, compostos de células com citoplasma eosinofílico e abundante, núcleo grande e ovoide com nucléolo proeminente, leve pleomorfismo nuclear e celular e baixa atividade mitótica. Também foi possível observar papilares do epitélio no lúmen, as quais são sustentadas por estroma fibrovascular, enquanto os carcinomas ductais com diferenciação escamosa foram caracterizados por possuírem lumens dispostos em dupla camada de células epiteliais e contendo secreção eosinofílica. As células exibiram moderado pleomorfismo nuclear, hipercromasia e leve atividade mitótica, associado à presença de focos de diferenciação escamosa.

Os tumores das glândulas hepatoides representaram 40,74\% (11/27) dos tumores cutâneos em cães. A positividade e a imurreatividade à CK14, à vimentina, ao p63, ao EGRF e ao índice Ki-67 estão distribuídas na Tab. 3. No entanto, nos tumores benignos, o índice de $\mathrm{Ki}-67$ foi leve em 16,67\% (1/6), moderado em 33,33\% (2/6) e acentuado em $50,00 \%$ (3/6). Os tumores malignos 
apresentaram proliferação Ki-67 acentuada em 100,0\% (5/5) dos casos (Fig. 1 e 2).

Os tumores das glândulas sebáceas representaram 29,63\% (8/27) dos casos. A positividade e a imurreatividade à CK14, à vimentina, ao p63, ao EGRF e ao índice Ki-67 estão distribuídas na Tab. 4. O índice Ki-67 foi leve em 50,00\% (2/4), moderado em $25,00 \%$ (1/4) e acentuado em $25,50 \%$ (1/4) dos tumores benignos. No entanto, nos tumores malignos, o índice de Ki-67 foi acentuado em 100,0\% (4/4) dos casos (Fig. 1 e 2).

O tumor da glândula de meibômio representou $3,70 \%(1 / 27)$ dos casos. A positividade e a imurreatividade à CK14, à vimentina, ao p63, ao EGRF e ao índice Ki-67 estão distribuídas na Tab. 5. O Ki-67 foi positivo, apresentando um índice de Ki-67 acentuado (Fig. 1 e 2).

Os tumores das glândulas sudoríparas apócrinas representaram 25,92\% (7/27) dos casos. A positividade e a imurreatividade à CK14, à vimentina, ao p63, à calponina, ao EGRF e ao índice Ki-67 estão distribuídas na Tab. 6. Os tumores benignos apresentaram índice de $\mathrm{Ki}-67$ moderado em 50,00\% (1/2) e acentuado em $50,00 \%(1 / 2)$. Nos tumores malignos, o índice de Ki-67 apresentou-se acentuado em 100,0\% (4/4) dos casos (Fig. 1 e 2).

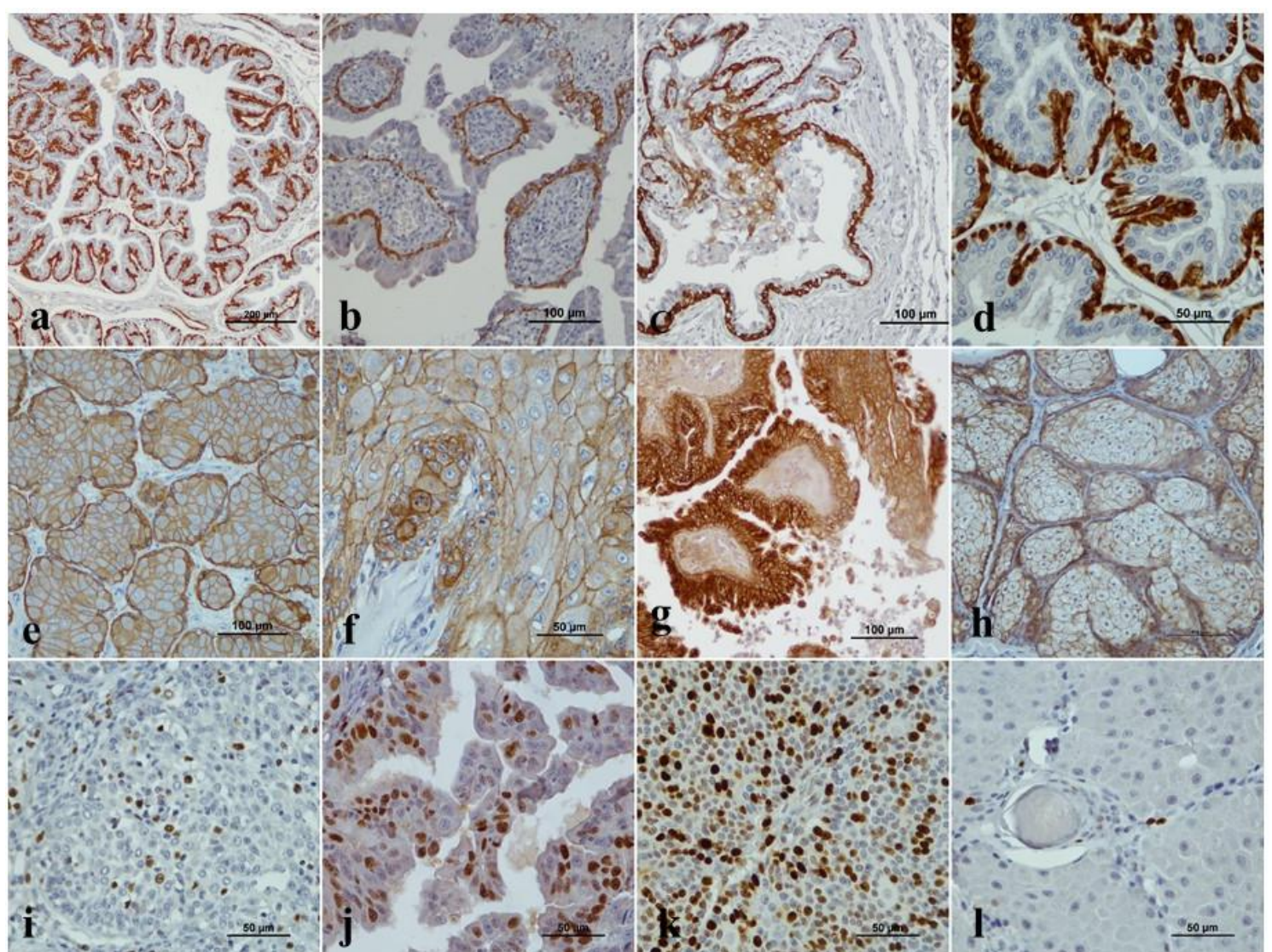

Figura 2. Tumores das glândulas cutâneas em cães: expressão imuno-histoquímica de calponina, EGFR e Ki-67. a) Adenoma quístico da glândula apócrina, positivo para calponina. 10x. Caso 15. b) Carcinoma papilar da glândula apócrina, positivo para calponina. 20x. Caso 14. c) Carcinoma ductal da glândula apócrina com focos de diferenciação escamosa, positivo para calponina. 20x. Caso 3. d) Adenoma cístico da glândula sudorípara apócrina, positivo para calponina. 40x. Caso 15. e) Adenoma da glândula hepatoide, positivo para EGFR. 20x. Caso 11. f) Carcinoma da glândula hepatoide, positivo para EGFR. 40x. Caso 7. g) Carcinoma ductal das glândulas sudoríparas apócrinas com focos de diferenciação escamosa, positivo para EGFR. 20x. Caso 9. h) Hiperplasia da glândula sebácea, positiva para EGFR. 20x. Caso 26. i) Carcinoma da glândula sebácea, positivo para Ki-67. 40x. Caso 25. j) Carcinoma papilar da glândula sudorípara apócrina, positivo para Ki-67. 40x. Caso 14. k) Epitelioma da glândula sebácea, positivo para Ki-67. 40x. Caso 20. 1) Hiperplasia da glândula hepatoide, positiva para Ki-67. 40x. Caso 23. 


\section{Vasconcelos et al.}

Tabela 3. Expressão dos anticorpos CK14, vimentina, p63, EGRF e índice Ki-67 em tumores das glândulas hepatoides em cães

\begin{tabular}{|c|c|c|c|c|c|c|c|c|c|}
\hline \multirow{3}{*}{$\mathrm{N}^{\mathrm{o}}$ dos $\operatorname{casos}^{*}$} & \multicolumn{9}{|c|}{ Anticorpos } \\
\hline & \multicolumn{2}{|c|}{ CK14 } & \multicolumn{2}{|c|}{ Vimentina } & \multicolumn{2}{|c|}{ p63 } & \multicolumn{2}{|c|}{ EGFR } & \multirow{2}{*}{$\frac{\mathrm{Ki}-67}{\text { (índice) }}$} \\
\hline & CEB & CDS & CEB & CDS & CEB & CDS & CEB & $\mathrm{CDS}$ & \\
\hline 02 & +++ & +++ & +++ & --- & +++ & + & +++ & +++ & +++ \\
\hline 04 & +++ & +++ & + & --- & +++ & ++ & +++ & +++ & +++ \\
\hline 07 & +++ & +++ & +++ & --- & +++ & ++ & +++ & +++ & +++ \\
\hline 10 & +++ & +++ & ++ & ++ & +++ & ++ & +++ & +++ & +++ \\
\hline 11 & +++ & + & +++ & --- & +++ & ++ & ++ & +++ & +++ \\
\hline 12 & +++ & +++ & +++ & --- & +++ & + & +++ & +++ & +++ \\
\hline 13 & +++ & +++ & +++ & ++ & +++ & ++ & +++ & ++ & +++ \\
\hline 16 & +++ & + & +++ & + & +++ & ++ & +++ & +++ & ++ \\
\hline 17 & +++ & +++ & +++ & + & +++ & + & +++ & +++ & +++ \\
\hline 22 & +++ & +++ & +++ & + & +++ & + & +++ & +++ & ++ \\
\hline 23 & +++ & ++ & ++ & + & +++ & + & + & +++ & + \\
\hline $\begin{array}{c}\text { Total/positivos } \\
\left(\% / \mathrm{n}^{\circ}\right)\end{array}$ & $\begin{array}{l}100,0 \\
(11 / 11)\end{array}$ & $\begin{array}{c}100,0 \\
(11 / 11)\end{array}$ & $\begin{array}{c}100,0 \\
(11 / 11)\end{array}$ & $\begin{array}{l}54,54 \\
(6 / 11)\end{array}$ & $\begin{array}{c}100,0 \\
(11 / 11)\end{array}$ & $\begin{array}{c}100,0 \\
(11 / 11)\end{array}$ & $\begin{array}{l}100,0 \\
(11 / 11)\end{array}$ & $\begin{array}{c}100,0 \\
(11 / 11)\end{array}$ & $\begin{array}{l}100,0 \\
(11 / 11)\end{array}$ \\
\hline \multicolumn{10}{|c|}{ Imunorreatividade $\left(\% / \mathrm{n}^{\circ}\right)$} \\
\hline$(+++)$ & $\begin{array}{c}100,0 \\
(11 / 11) \\
(11 / 11)\end{array}$ & $\begin{array}{l}72,72 \\
(8 / 11) \\
(8 / 11)\end{array}$ & $\begin{array}{c}72,72 \% \\
(8 / 11) \\
(8 / 11)\end{array}$ & ---- & $\begin{array}{c}100,0 \\
(11 / 11) \\
(11 / 11)\end{array}$ & ---- & $\begin{array}{l}81,82 \\
(9 / 11) \\
(9 / 11)\end{array}$ & $\begin{array}{c}90,91 \\
(10 / 11) \\
(10 / 11)\end{array}$ & $\begin{array}{c}72,72 \\
(8 / 11) \\
(8 / 11)\end{array}$ \\
\hline$(++)$ & --- & $\begin{array}{c}9,09 \\
(1 / 11) \\
(1 / 11)\end{array}$ & $\begin{array}{l}18,18 \\
(2 / 11) \\
(2 / 11)\end{array}$ & $\begin{array}{c}33,33 \\
(2 / 6) \\
(2 / 6)\end{array}$ & (1) & $\begin{array}{l}54,54 \\
(6 / 11) \\
(6 / 11)\end{array}$ & $\begin{array}{c}9,09 \\
(1 / 11) \\
(1 / 11)\end{array}$ & $\begin{array}{c}9,09 \\
(1 / 11) \\
(1 / 11)\end{array}$ & $\begin{array}{l}18,18 \\
(2 / 11) \\
(2 / 11)\end{array}$ \\
\hline$(+)$ & ---- & $\begin{array}{l}18,18 \\
(2 / 11) \\
(2 / 11)\end{array}$ & $\begin{array}{c}9,09 \\
(1 / 11) \\
(1 / 11)\end{array}$ & $\begin{array}{l}66,67 \\
(4 / 6) \\
(4 / 6)\end{array}$ & ---- & $\begin{array}{l}45,46 \\
(5 / 11) \\
(5 / 11)\end{array}$ & $\begin{array}{c}9,09 \\
(1 / 11) \\
(1 / 11)\end{array}$ & --- & $\begin{array}{c}9,10 \\
(1 / 11) \\
(1 / 11)\end{array}$ \\
\hline
\end{tabular}

$\mathrm{CEB}=$ células epiteliais basais; $\mathrm{CDS}=$ células de diferenciação sebácea; $+++=$ acentuada $;++=$ moderada; $+=$ leve .

Tabela 4. Expressão dos anticorpos CK14, vimentina, p63, EGRF e índice Ki-67 em tumores das glândulas sebáceas em cães

\begin{tabular}{|c|c|c|c|c|c|c|c|c|c|}
\hline \multirow{3}{*}{$\mathrm{N}^{\mathrm{o}}$ dos casos ${ }^{*}$} & \multicolumn{9}{|c|}{ Anticorpos } \\
\hline & \multicolumn{2}{|c|}{ CK14 } & \multicolumn{2}{|c|}{ Vimentina } & \multicolumn{2}{|c|}{ p63 } & \multicolumn{2}{|c|}{ EGFR } & \multirow{2}{*}{$\begin{array}{c}\text { Ki-67 } \\
\text { (índice) }\end{array}$} \\
\hline & CEB & CDS & CEB & $\mathrm{CDS}$ & CEB & CDS & CEB & CDS & \\
\hline 01 & +++ & +++ & --- & --- & +++ & --- & ++ & --- & + \\
\hline 05 & +++ & +++ & --- & --- & --- & --- & --- & +++ & + \\
\hline 06 & +++ & ++ & --- & --- & +++ & --- & +++ & +++ & +++ \\
\hline 18 & +++ & + & ++ & --- & +++ & + & +++ & --- & +++ \\
\hline 20 & +++ & +++ & +++ & --- & +++ & + & +++ & +++ & +++ \\
\hline 25 & +++ & ++ & +++ & --- & +++ & +++ & +++ & +++ & +++ \\
\hline 26 & +++ & +++ & --- & --- & ++ & --- & +++ & +++ & ++ \\
\hline 27 & +++ & +++ & +++ & --- & +++ & --- & +++ & + & +++ \\
\hline Total/ & 100,0 & 100,0 & 50,0 & & 87,50 & 37,50 & 87,50 & 75,00 & 100,0 \\
\hline Posit. $^{\mathrm{b}}\left(\% / \mathrm{n}^{\mathrm{o}}\right)$ & $(8 / 8)$ & $(8 / 8)$ & $(4 / 8)$ & -- & $(7 / 8)$ & $(3 / 8)$ & $(7 / 8)$ & $(6 / 8)$ & $(8 / 8)$ \\
\hline \multicolumn{10}{|c|}{ Imunorreatividade $\left(\% / \mathrm{n}^{\mathrm{o}}\right)$} \\
\hline \multirow{3}{*}{$(+++)$} & 100,0 & 62,50 & 75,00 & & 85,71 & 33,33 & 85,71 & 83,33 & 62,50 \\
\hline & $(11 / 11)$ & $(8 / 11)$ & $(3 / 4)$ & --- & $(6 / 7)$ & $(1 / 3)$ & $(6 / 7)$ & $(5 / 6)$ & $(5 / 8)$ \\
\hline & $(8 / 8)$ & $(5 / 8)$ & $(3 / 4)$ & & $(6 / 7)$ & $(1 / 3)$ & $(6 / 7)$ & $(5 / 6)$ & $(5 / 8)$ \\
\hline \multirow{3}{*}{$(++)$} & --_- & 12,50 & 25,00 & - & 14,29 & - & 14,29 & & 12,50 \\
\hline & --- & $(1 / 11)$ & $(1 / 4)$ & --- & $(1 / 7)$ & -- & $(1 / 7)$ & & $(1 / 8)$ \\
\hline & & $(1 / 8)$ & $(1 / 4)$ & & $(1 / 7)$ & & $(1 / 7)$ & & $(1 / 8)$ \\
\hline \multirow{3}{*}{$(+)$} & - & 25,00 & & & & 66,67 & 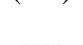 & 16,67 & 25,00 \\
\hline & ---- & $(2 / 11)$ & ---- & -- & ---- & $(2 / 3)$ & --- & $(1 / 6)$ & $(2 / 8)$ \\
\hline & & $(2 / 8)$ & & & & $(2 / 3)$ & & $(1 / 6)$ & $(2 / 8)$ \\
\hline
\end{tabular}

$\mathrm{CEB}=$ células epiteliais basais; $\mathrm{CDS}=$ células de diferenciação sebácea; $(+++)=$ acentuada; $(++)=$ moderada; $(+)=$ leve. 
Caracterização anatomopatológica...

Tabela 5. Expressão dos anticorpos CK14, vimentina, p63, EGRF e índice Ki-67 em tumor da glândula de meibômio em cães

\begin{tabular}{|c|c|c|c|c|c|c|c|c|c|}
\hline \multirow{3}{*}{$\begin{array}{l}\mathrm{N}^{\mathrm{o}} \text { dos } \\
\text { Casos }\end{array}$} & \multicolumn{9}{|c|}{ Anticorpos } \\
\hline & \multicolumn{2}{|c|}{ CK14 } & \multicolumn{2}{|c|}{ Vimentina } & \multicolumn{2}{|c|}{ p63 } & \multicolumn{2}{|c|}{ EGFR } & Ki-67 \\
\hline & CEB & CDS & CEB & CDS & CEB & CDS & CEB & CDS & (índice) \\
\hline 19 & +++ & +++ & +++ & + & +++ & + & +++ & ++ & +++ \\
\hline $\begin{array}{l}\text { Total/ } \\
\text { Posit. } \\
\left(\% / n^{\circ}\right)\end{array}$ & $100,0(1 / 1)$ & $\begin{array}{c}100,0 \\
(1 / 1)\end{array}$ & $\begin{array}{c}100,0 \\
(1 / 1)\end{array}$ & $\begin{array}{c}100,0 \\
(1 / 1)\end{array}$ & $\begin{array}{c}100,0 \\
(1 / 1)\end{array}$ & $\begin{array}{c}100,0 \\
(1 / 1)\end{array}$ & $\begin{array}{c}100,0 \\
(1 / 1)\end{array}$ & $\begin{array}{c}100,0 \\
(1 / 1)\end{array}$ & $\begin{array}{c}100,0 \\
(1 / 1)\end{array}$ \\
\hline \multicolumn{10}{|c|}{ Imunorreatividade $\left(\% / \mathrm{n}^{\mathrm{o}}\right)$} \\
\hline$(+++)$ & $\begin{array}{c}100,0 \\
(11 / 11) \\
(1 / 1)\end{array}$ & $\begin{array}{l}100,0 \\
(1 / 1) \\
(1 / 1)\end{array}$ & $\begin{array}{l}100,0 \\
(1 / 1) \\
(1 / 1)\end{array}$ & ---- & $\begin{array}{c}100,0 \\
(1 / 1) \\
(1 / 1)\end{array}$ & ---- & $\begin{array}{l}100,0 \\
(1 / 1) \\
(1 / 1)\end{array}$ & ---- & $\begin{array}{l}100,0 \\
(1 / 1) \\
(1 / 1)\end{array}$ \\
\hline$(++)$ & ---- & --- & --- & ---- & --- & ---- & --- & $\begin{array}{c}100,0 \\
(1 / 1) \\
(1 / 1)\end{array}$ & ---- \\
\hline$(+)$ & ---- & ---- & --- & $\begin{array}{l}100,0 \\
(1 / 1) \\
(1 / 1)\end{array}$ & ---- & $\begin{array}{c}100,0 \\
(1 / 1) \\
(1 / 1)\end{array}$ & ---- & ---- & ---- \\
\hline
\end{tabular}

CEB = células epiteliais basais; $\mathrm{CDS}$ = células de diferenciação sebácea; +++ = acentuada; ++ = moderada; + = leve.

Tabela 6. Expressão dos anticorpos CK14, vimentina, p63, calponina, vimentina, EGRF e índice Ki-67 em tumores das glândulas sudoríparas apócrinas em cães

\begin{tabular}{|c|c|c|c|c|c|c|c|c|c|c|c|}
\hline \multirow{3}{*}{$\begin{array}{c}\mathrm{N}^{\mathrm{O}} \\
\mathrm{dos} \\
\text { casos }^{*}\end{array}$} & \multicolumn{11}{|c|}{ Anticorpos } \\
\hline & \multicolumn{2}{|c|}{ CK14 } & \multicolumn{2}{|c|}{ Vimentina } & \multicolumn{2}{|c|}{ p63 } & \multicolumn{2}{|c|}{ Calponina } & \multicolumn{2}{|c|}{ EGFR } & \multirow{2}{*}{$\frac{\mathrm{Ki}-67}{\text { (índice) }}$} \\
\hline & $\mathrm{CM}$ & CL & $\mathrm{CM}$ & CL & $\mathrm{CM}$ & $\mathrm{CL}$ & $\mathrm{CM}$ & CL & $\mathrm{CM}$ & CL & \\
\hline 03 & +++ & + & +++ & --- & +++ & --- & +++ & ---- & +++ & +++ & +++ \\
\hline 08 & +++ & --- & +++ & --- & +++ & --- & +++ & ---- & +++ & +++ & $-{ }^{\mathrm{a}}$ \\
\hline 09 & +++ & --- & +++ & + & +++ & --- & +++ & ---- & + & +++ & +++ \\
\hline 14 & +++ & --- & +++ & --- & +++ & --- & +++ & ---- & +++ & + & +++ \\
\hline 15 & +++ & + & +++ & --- & +++ & --- & +++ & ---- & +++ & --- & +++ \\
\hline 21 & +++ & ++ & +++ & --- & +++ & --- & +++ & ---- & ++ & ++ & ++ \\
\hline 24 & +++ & + & +++ & + & +++ & --- & +++ & ---- & +++ & --- & +++ \\
\hline $\begin{array}{l}\text { Total/ } \\
\text { Posit. } \\
\left(\% / \text { n }^{\circ}\right)\end{array}$ & $\begin{array}{c}100,0 \\
(7 / 7)\end{array}$ & $\begin{array}{l}57,14 \\
(4 / 7)\end{array}$ & $\begin{array}{c}100,0 \\
(7 / 7)\end{array}$ & $\begin{array}{c}28,57 \\
(2 / 7)\end{array}$ & $\begin{array}{c}100,0 \\
(7 / 7)\end{array}$ & ---- & $\begin{array}{c}100 \\
(7 / 7)\end{array}$ & ---- & $\begin{array}{c}100 \\
(7 / 7)\end{array}$ & $\begin{array}{c}71,43 \\
(5 / 7)\end{array}$ & $\begin{array}{c}87,50 \\
(7 / 8)\end{array}$ \\
\hline \multicolumn{12}{|c|}{ Imunorreatividade $\left(\% / \mathrm{n}^{\circ}\right)$} \\
\hline$(+++)$ & $\begin{array}{c}100,00 \\
(7 / 7) \\
(7 / 7)\end{array}$ & --- & $\begin{array}{l}100,0 \\
(7 / 7) \\
(7 / 7)\end{array}$ & ---- & $\begin{array}{l}100,0 \\
(7 / 7)\end{array}$ & ---- & $\begin{array}{c}100 \\
(7 / 7) \\
(7 / 7)\end{array}$ & ---- & $\begin{array}{c}71,42 \\
(5 / 7) \\
(5 / 7)\end{array}$ & $\begin{array}{l}60,00 \\
(3 / 5) \\
(3 / 5)\end{array}$ & $\begin{array}{c}83,33 \\
(5 / 6) \\
(5 / 6)\end{array}$ \\
\hline$(++)$ & --- & $\begin{array}{c}25,00 \\
(1 / 4) \\
(1 / 4)\end{array}$ & --- & ---- & --- & ---- & --- & ---- & $\begin{array}{l}14,29 \\
(1 / 7) \\
(1 / 7)\end{array}$ & $\begin{array}{c}20,00 \\
(1 / 5) \\
(1 / 5)\end{array}$ & $\begin{array}{l}16,67 \\
(1 / 6) \\
(1 / 6)\end{array}$ \\
\hline$(+)$ & ---- & $\begin{array}{l}75,00 \\
(3 / 4) \\
(3 / 4)\end{array}$ & ---- & $\begin{array}{l}100,0 \\
(2 / 2) \\
(2 / 2)\end{array}$ & ----- & ---- & ---- & ---- & $\begin{array}{c}14,29 \\
(1 / 7) \\
(1 / 7)\end{array}$ & $\begin{array}{c}20,00 \\
(1 / 5)) \\
(1 / 5)\end{array}$ & ---- \\
\hline
\end{tabular}

$\mathrm{CM}=$ células mioepiteliais; $\mathrm{CL}=$ células luminais; $(\mathrm{p} / \mathrm{n})=$ positivo/negativo; $+++=$ acentuada $;++=$ moderada; $+=$ leve; '(índice excluído devido à negatividade na epiderme, o qual funciona como controle positivo interno) e bositivos.

\section{DISCUSSÃO}

No presente estudo, os tumores de glândulas cutâneas de origem sebácea foram superiores aos de origem apócrina. Resultados semelhantes foram observados por Saraiva (2007), que realizaram um estudo retrospectivo coletando dados por um período de 10 anos. No entanto, o número de amostras no presente estudo foi menor, não sendo diagnosticados casos de tumores apócrinos modificados. Não se verificou predisposição racial, devido ao fato de a maioria dos cães não ter raça definida e ao reduzido número de casos estudados. No entanto, estudos 
citam algumas raças, como Cocker Spaniel Inglês, Cocker Spaniel, Poodle, Beagle, Samoieda, Husky Siberiano, Malamute do Alasca, West Highland White Terrier, Cairn Terrier, Dachshund, Kerry Blue Terrier, Schnauzer, Boston Terrier e Shih-Tzu, com elevado risco para desenvolver esses tumores e outras descritas com baixo risco de desenvolvimento dos mesmos tumores (Thomas e Fox, 1998; Scott et al., 2001; Goldschmidt e Hendrick, 2002; Gross et al., 2005).

Clinicamente, os tumores apresentavam-se como lesões nodulares cutâneas ulceradas e não ulceradas, distribuídas em vários sítios anatômicos, variando o tamanho de milímetros a centímetros (Goldschmidt e Hendrick, 2002; Gross et al., 2005). A distribuição anatômica dos tumores no presente estudo foi semelhante à observada por Saraiva (2007), entretanto há autores que relatam que a localização preferencial desses tumores é as regiões axilar e inguinal (Goldschmidt e Hendrick, 2002) e os membros (Gross et al., 2005). Outros estudos, porém, apontam que eles ocorrem em qualquer localização (Pulley e Stannard, 1990; Kalaher et al., 1990 e Simko et al., 2003).

A avaliação imuno-histoquímica permitiu a obtenção de resultados descritivos dos 27 tumores estudados, com uma melhor caracterização e interpretação dos elementos capazes de favorecer um diagnóstico mais preciso. Todavia, nem sempre esses resultados são específicos ou conclusivos. No presente estudo, o anticorpo antiqueratina 14 (CK14) foi positivo em todos os tumores das glândulas sebáceas e sebáceas modificadas (hepatoides e meibômio) com imunomarcação das células epiteliais basais e das células de diferenciação sebácea. Esses resultados assemelham-se aos descritos na literatura (Walter, 2000; Vos et al., 1993 e Saraiva, 2007). No entanto, as células de diferenciação sebácea do tumor da glândula de meibômio (caso 19) foram acentuadamente mais imunorreativas. Esse fato provavelmente se deve a características próprias do tumor e/ou a modificações fenotípicas em células basaloides. Nos tumores das glândulas sudoríparas apócrinas, o anticorpo CK14 foi positivo em todos os casos estudados, apresentando positividade para as células mioepiteliais e as epiteliais luminais (secretoras). Em outros estudos, entretanto, a imunomarcação das células luminais (secretoras) não foi observada, tanto no homem quanto no cão e no gato (Espinosa de Los Monteros et al., 2002; Gama et al., 2003; Araújo et al., 2006; Faustino e Dias Pereira, 2007). A marcação das células luminais (secretoras) está associada a modificações fenotípicas de tumores apócrinos. O mesmo fato ocorreu em células epiteliais luminais de carcinomas complexos da mama de gatas (Seixas et al., 2008).

A vimentina é expressa nas glândulas hepatoides normais e em outras glândulas sebáceas modificadas (Vos et al., 1993). Essa característica foi demonstrada no presente estudo com a positividade em $100 \%$ dos tumores hepatoides, que, além do estroma, também apresentaram imunorreatividade nas células epiteliais basais e nas células de diferenciação sebácea. Resultados semelhantes foram descritos por Alves (1999) e Saraiva (2007). No presente trabalho, os tumores sebáceos foram positivos em 50,00\% dos casos (nos casos 18, 20, 25 e 27), apresentando imunomarcação nas células epiteliais basais e não expressando a vimentina nas células de diferenciação sebácea. No entanto, a imunomarcação se deu apenas nos tumores malignos. Esse fato é consequência da modificação fenotípica epitelial mesenquimal que ocorre em adenocarcinomas sebáceos, tanto em animais quanto em seres humanos (Saraiva, 2007; Shinozak et al., 2008).

No presente estudo, o epitelioma da glândula de meibômio (caso 19) expressou a vimentina, mantendo o mesmo padrão e as características descritas por Vos et al. (1993). Os mesmos resultados não foram observados em estudos com carcinomas de glândulas sebáceas modificadas, adenocarcinomas de meibômio em cães (Varga et al., 2000) e carcinoma sebáceo mamário de mulher (Yuan et al., 2008).

Todos os tumores apócrinos demonstraram-se positivos à vimentina com imunomarcação das células mioepiteliais em todos os casos, porém em apenas dois casos (casos 08 e 24) houve imunomarcação das células epiteliais luminais. Em relação à imunomarcação das células mioepiteliais, esses resultados corroboram os descritos em glândulas mamárias de cadelas (Gärtner et al., 1999 e Gama et al., 2003) e em tumores das glândulas apócrinas de cães (Ferrer et al., 1990; Nibe et al., 2005 e Saraiva, 2007). 
Em um estudo com carcinomas complexos da glândula mamária de gatas, há referência à imunomarcação em células epiteliais luminais pela vimentina (Seixas et al., 2008). A marcação das células epiteliais luminais pela vimentina pode estar associada à transição epitelialmesenquimatosa, à histogênese mioepitelial e à histogênese a partir de células com potencial de diferenciação bilinear (Korsching et al., 2005). No entanto, não há dados que fundamentem a origem das células epiteliais positivas para a vimentina nos adenocarcinomas cutâneos do cão.

O gene p63 é expresso nas células basais estaminais de vários órgãos epiteliais, desempenhando uma função importante na manutenção do compartimento das células estaminais nesses órgãos (Barbareschi et al., 2001). No presente estudo, a expressão do p63 nos tumores das glândulas sebáceas, hepatoides e de meibômio ocorreu em todos os casos estudados, marcando as células epiteliais basais e as células de diferenciação sebácea. Resultados semelhantes foram observados por Saraiva (2007) em tumores malignos sebáceos e hepatoides e em carcinomas sebáceos no homem (Qureshi et al., 2004).

Nos tumores apócrinos, a imunoexpressão do p63 ocorreu em todos os casos, entretanto só as células mioepiteliais foram positivas. Esses resultados mantêm o mesmo padrão e as características do anticorpo em relação às glândulas apócrinas e às glândulas apócrinas modificadas descritas na literatura (Barbareschi et al., 2001). Resultados semelhantes foram encontrados em tumores de glândula mamária de cadela (Gama et al., 2003), em tumores malignos de glândulas apócrinas cutâneas (Saraiva, 2007) e em tumores apócrinos no homem (Qureshi et al., 2004; Ivan et al., 2005).

A calponina é uma proteína que interage na contração da musculatura lisa, sendo expressa nas células mioepiteliais. No presente estudo, a calponina foi utilizada apenas nos tumores apócrinos, sendo expressa nas células mioepiteliais de todos os casos. No entanto, além da imunomarcação dos tumores apócrinos, a calponina também foi evidenciada em áreas de diferenciação escamosa, em células vasculares no estroma e em proliferações sólidas de células mioepiteliais. Essas características se devem à capacidade de diferenciação epitelial-mioepilial, que pode ocorrer em tumores apócrinos malignos (Gimona et al., 1990). Em outros estudos foram verificadas as mesmas características, em que a calponina foi expressa em tumores mamários complexos e mistos de cadelas e em tumores malignos de glândulas apócrinas e ceruminosas de cães (Espinosa de Los Monteros et al., 2002; Saraiva et al., 2008).

Não foi encontrado nenhum trabalho sobre avaliação da expressão do EGFR em glândulas cutâneas de animais, por isso considera-se este o primeiro trabalho nesse sentido. O EGFR foi positivo em todos os tumores das glândulas hepatoides, sebáceas e de meibômio, apresentando imunomarcação tanto nos tumores malignos quanto nos benignos. A distribuição da imunomarcação pelo EGFR ocorreu nas células epiteliais basais e nas células de diferenciação sebácea. Entretanto, em dois casos (01 e 18) de tumores sebáceos, não houve imunomarcação das células de diferenciação sebácea. Em estudo com tumores sebáceos benignos e malignos, a imunomarcação ocorreu tanto nas células epiteliais basais quanto nas de diferenciação sebácea. No entanto, a imunomarcação foi mais intensa nos tumores malignos em relação aos benignos (Matias e Orentreich, 1983). No presente estudo, porém, não se verificou essa relação. Tal fato provavelmente esteja relacionado a características próprias dos tumores estudados e ao pequeno número de casos. Os tumores das glândulas apócrinas foram positivos ao EGFR em todos os casos, ocorrendo imunomarcação das células mioepiteliais e das células epiteliais luminais (secretoras), no entanto, em dois casos (21 e 24), foram negativos para as células epiteliais luminais. Provavelmente essa negatividade esteja associada à inatividade da tirosina quinase nos dois casos, consequentemente, faltam receptores para o EGFR desempenhar sua função (Bhargava et al., 2005). Gama et al. (2009) estudaram a expressão do EGFR na glândula mamária de cadelas (hiperplasia, tumores benignos e malignos) e encontraram resultados semelhantes aos do presente estudo.

Os índices proliferativos elevados, obtidos pela imunoexpressão do anticorpo anti-Ki-67, estão associados ao comportamento biológico do tumor, ao comportamento clinicopatológico maligno e a um pior prognóstico de vários tumores nos animais domésticos (Geraldes et al., 
2000). Na avaliação do índice Ki-67, foi possível observar que a imunomarcação comportou-se da mesma forma em todos os grupos de tumorais estudados. Nos tumores malignos, o índice de Ki-67 foi acentuado em todos os casos. Nos tumores benignos, o índice $\mathrm{Ki}-67$ variou de leve, moderado a acentuado. Outros estudos obtiveram resultados semelhantes em tumores de glândulas hepatoides e em epiteliomas sebáceos de cães (Alves, 1999; Yoon e Park, 2016). Em tumores mamários caninos, os índices de proliferação usando a detecção imuno-histoquímica do Ki-67 foram mais intensos nos tumores malignos em relação aos benignos (Peña et al., 1998). No entanto, em tumores hepatoide caninos, aspectos como infiltração, invasão e perda da lobulação influenciaram para o índice de Ki-67 elevado (Alves, 1999). Peña et al. (1998) observaram que valores altos do índice de Ki-67 estavam diretamente relacionados com fatores como metástases, morte por neoplasia, baixas taxas de sobrevivência livres de doença e, em geral, com baixas taxas de sobrevivência. Entretanto, no presente estudo, devido ao número reduzido das amostras, não se fez estudo estatístico dos aspectos clínicos ou morfológicos, detendo-se apenas na caracterização histológica e imunohistoquímica.

\section{CONCLUSÕES}

Conclui-se que os tumores das glândulas cutâneas afetam cães de qualquer raça e não apresentam predisposição por sexo. Porém, os cães com idade igual ou superior a sete anos são mais afetados. Entre os tipos de tumores glandulares cutâneos, os mais frequentes foram os tumores das glândulas hepatoides, seguidos dos tumores sebáceos, tumores apócrinos e tumores da glândula de meibômio. Todos esses tumores tiveram apresentação nodular subcutânea, com superfície ulcerada ou não. O painel imuno-histoquímico variou entre os diferentes tipos de tumores. $\mathrm{O}$ anticorpo antiCK14 foi expresso de forma acentuada nas células basais, células de diferenciação sebácea e células mioepiteliais, porém não apresentou marcação exclusiva. A vimentina marca satisfatoriamente as células basais dos tumores das glândulas hepatoides e de meibômio, mas o mesmo fato não ocorre nos tumores sebáceos. Nos tumores das glândulas apócrinas, esse anticorpo é um marcador sensível para as células mioepiteliais. O anticorpo p63 é um marcador sensível e específico de células basais e de células mioepiteliais dos tumores de glândulas cutâneas. A calponina marca as células mioepiteliais das glândulas apócrinas. O anticorpo EGFR é sensível para as células basais e de diferenciação sebácea dos tumores das glândulas hepatoides e de meibômio, mas a mesma sensibilidade não ocorre nos tumores sebáceos. Nos tumores apócrinos, esse marcador é sensível para as células mioepiteliais, no entanto, nas células epiteliais luminais, não foi observada a mesma sensibilidade. $\mathrm{O}$ índice de marcação de Ki-67 foi mais acentuado nos tumores malignos em todos os grupos de tumores de glândulas cutâneas estudados. Estudos futuros com maior número de casos, correlacionando dados epidemiológicos, clínicos, dermatológicos, patológicos (macroscopia e microscopia) e imuno-histoquímicos, fazem-se necessários.

\section{AGRADECIMENTOS}

À Coordenação de Aperfeiçoamento de Pessoal de Nível Superior (Capes), pela concessão da bolsa de estudos; ao Programa de Pós-Graduação em Medicina Veterinária (PPGMV); ao Laboratório de Histologia e Anatomia Patológica (LHAP) da Universidade de Trás-os-Montes e Alto Douro - Vila Real, Portugal; e à Lígia Lourenço, técnica em anatomia patológica. Ao CNPq, pela Bolsa de Produtividade do Orientador (Processo n ${ }^{0}$ 302082/2014-0).

\section{REFERÊNCIAS}

ALVES, A.G.A. Estudo histológico e imunohistoquímico dos tumores das glândulas hepatoides caninas: marcadores celulares, fracção do crescimento, gene supressor p53 e hormonodependência. Relação com os aspectos clínicos. 1999. 234f. Tese (Doutoramento em Medicina Veterinária) - Centro de Ciência Anima e Veterinária - Universidade de Trás-osMontes e Alto Douro, Vila Real, POR.

ARAÚJO, VC.; ALTEMANI, A.; FURUSE, C. et al. Immunoprofile of reactive salivary myoepithelial cells in intraductal areas of carcinoma ex-pleomorphic adenoma. Oral Oncol., v.42, p.1011-1016, 2006. 
BARBARESCHI, M.; PECCIARINI, L.; CANGI, M.G. et al. p63, a p53 homologue, is a selective nuclear marker of myoepithelial cells of the human breast. Am. J. Surg. Pathol., v.25, p.1054-1060, 2001.

BHARGAVA, R.; GERALD, W.L.; LI, A.R. et al. EGFR gene amplification in breast cancer: correlation with epidermal growth factor receptor mRNA and protein expression and HER-2 status and absence of EGFR activating mutations. Modern Pathol., v.18, v.1027-1033, 2005.

ESPINOSA DE LOS MONTEROS, A.; MILLÁN, M.Y.; ORDÁS, J. et al. Immunolocalization of the smooth musclespecific protein calponin in complex and mixed tumors of the mammary gland of the dog: assessment of the morphogenetic role of the myoepithelium. Vet. Pathol., v.39, p.247-256, 2002.

FAUSTINO, A.M.; DIAS PEREIRA, P.A. Salivary malignant myoepithelioma in a dog. Vet. J., v.173, p.225-228, 2007.

FERRER, L.; RABANAL, R.M.; FONDEVILA, D. Immunocytochemical demonstration of intermediate filament proteins, S-100 protein and CEA in apocrine sweat glands and apocrine gland derived lesions of the dog. J. Vet. Med., v.37, p.569-576, 1990.

GAMA, A.; ALVES, A.; GÄRTNER, F. et al. p63: a novel myoepithelial cell marker in canine mammary tissues. Vet. Pathol., v.40, p.412-420, 2003.

GAMA, A.; GÄRTNER, F.; ALVES, A. et al. Immunohistochemical expression of Epidermal Growth Factor Receptor (EGFR) in canine mammary tissues. Res. Vet. Sci., v.87, p.432-437, 2009.

GÄRTNER, F.; GERALDES, M.; CASSALI, G. et al. Mesurement and immunohistochemical characterization of epithelial and mesenchymal cells in canine mixed mammary tumours: putative evidence for a common histogenesis. Vet. J., v.158, p.39-47, 1999.

GERALDES, M.; GÄRTNER, F.; SCHMITT, F. Immunohistochemical study of hormonal receptors and cell proliferation in normal canine mammary glands and spontaneous mammary tumours. Vet. Rec., v.146, p.403-406, 2000.
GIMONA, M.; HERZOG, M.; VANCEKERCKHOVE, J. et al. Smooth muscle specific expression of calponin. Fed. Eur. Biochem. Soc. Lett., v.274, p.159-162, 1990.

GOLDSCHMID, T.M.H.; DUNSTAN, R.W.; STANNARD, A.A. et al. Histological classification of epithelial and melanocytic tumors of the skin of domestic animals. Armed Forces Institute of Pathology in cooperation with the American Registry of pathology and the World Health Organization Collaborating Center for Worldwide Reference on Comparative Oncology. Washington: Armed, 1998. p.105.

GOLDSCHMIDT, M.H.; HENDRICK, M.J. Tumors of the skin and soft tissues. In: MEUTEN, D.J. 4.ed. Tumors in domestic animals. Ames: Wiley Blackwell, 2002. cap.2, p.45-74.

GROSS, T.L.; IHRKE, P.J.; WALDER, E.J. et al. Epithelial neoplasms and other tumors. Sebaceous tumors. Sweat gland tumors. In: GROSS T.L. Skin diseases of the dog and cat. Clinical and histopathologic diagnosis. 2.ed. Oxford: Blackwell Publishing, 2005. p.641-689.

IVAN, D.; DIWAN, A.H.; PRIETO, V.G. Expression of p63 in primary cutaneous adnexal neoplasms and adenocarcinoma metastatic to the skin. Modern Pathol., v.18, p.137-142, 2005.

KALAHER, K.M.; ANDERSON, W.I.; SCOTT, D.W. Neoplasms of the apocrine sweat glands in 44 dogs and 10 cats. Vet. Rec., v.127, p.400-403, 1990.

KIRPENSTEIJN, J. Tratment of aural neoplasia in dogs and cats. In: PROCEEDINGS OF THE NORTH AMERICAN VETERINARY CONFERENCE, 20., 2006, Orlando. Proceedings... Orlando: [s.n.], 2006. p.793-796.

MATIAS; J.R.; ORENTREICH, N. Stimulation of hamster sebaceous glands by epidermal growth factor. J. Invest. Dermatol., v.80, p.516, 1983.

NIBE, K.; UCHIDA, K.; ITOH, T. et al. A case of canine apocrine sweat gland adenoma, clear cell variant. Vet. Pathol., v.42, p.215-218, 2005.

PENÃ, L.L.; NIETO, A.I.; PÉREZ-ALENZA, D. et al. Immunohistochemical detection of $\mathrm{Ki}-67$ and PCNA in canine mammary tumors: relationship to clinical and pathologic variables. J. Vet. Diagn. Invest., v.10, p.237-246, 1998. 
PETTERINO, C.; MARTINI, M.; CASTAGNARO, M. Immunohistochemical detection of growth hormone $(\mathrm{GH})$ in canine hepatoid gland tumors. J. Vet. Med. Sci., v.66, p.569-572, 2004.

POLAK, J.M.; VAN NOORDEN, S. Introduction to immunocytochemistry. J. Anat., v.202, p.176, 2003.

PULLEY, L.T.; STANNARD, A. Tumors of the skin and soft tissues. In: MOULTON, J.E. Tumors in dosmetic animals. 3.ed. Berkeley and Los Angeles: University of California Press, 1990. p.23-72.

QURESHI, H.S.; ORMSBY, A.H.; LEE, M.W. et al. The diagnostic utility of p63, CK5/6, CK7, and CK20 in distinguishing primary cutaneous adnexal neoplasms from metastatic carcinomas. J. Cutan. Pathol., v.31, p.145-152, 2004.

SARAIVA, A.L. Contribuição para o estudo da biopatologia dos adenocarcinomas cutâneos em canídeos. 2007. 98f. Dissertação (Mestrado em Medicina Veterinária) - Faculdade de Medicina da Universidade do Porto, Porto, POR.

SARAIVA, A.L.; GÄRTNER, F.; PIRES, M.A. Expression of p63 normal canine skin and primary cutaneous glandular carcinoma. Vet. J., v.177, p.136-140, 2008.

SCOTT, D.W.; MILLER J.R.; W.H.; GRIFFIN, C.E. Neoplastic and non-neoplastic tumors. In: KERSEY, R. Muller \& Kirk's small animal dermatology. 6.ed. Philadelphia: W.B. Saunders Company, 2001. p.1-70.

SEIXAS, F.; PIRES, M.A.; LOPES, C.A. Complex carcinomas of the mammary gland in cats: Pathological and immunohistochemical features. Vet. J., v.176, p.210-215, 2008.

SHINOZAK, A.; NAGAO, T.; ENDO, H. et al. Sebaceous epithelial-myoepithelial carcinoma of the salivary gland: clinicopathologic and immunohistochemical analysis of 6 cases of a new histologic variant. Am. J. Surg. Pathol., v.32, p.913-926, 2008.
SIMKO, E.; WILCOCK B.P.; YAGER, J.A. A retrospective study of 44 canine apocrine sweat gland adenocarcinomas. Can. Vet. J., v.44, p.3842, 2003.

SISCHO, W.M.; IHRKE, P.J.E.; FRANTI, C.E. Regional distribution of 10 common skin diseases in dogs. J. Am. Vet. Med. Assoc., v.195, p.752-756, 1989.

THOMAS, C.; FOX, L.E. Tumors of the skin and subcutis. In: Morrison, W.B. Cancer in dogs and cats - medical and surgical management. [Jackson]: Teton New Media, 1998. p.489-499.

VARGA, Z.; KOLB, S.A; FLURY, R. et al. Sebaceous carcinoma of the breast. Pathol. Int., v.50, p.63-66, 2000.

VOS, J.H.; TSGAM VAN DEN, I.; RAMAEKERS, F.C.S. et al. The expression of keratins, vimentin, neurofilament proteins, smooth muscle actin, neuron-specific enolase, and synaptophysin in tumors of the specific glands in the canine anal region. Vet. Pathol., v.30, p.352-361, 1993.

WALTER, J.A. Cytokeratin profile of canine epithelial skin tumours. J. Comp. Pathol., v.122, p.278-287, 2000.

WITHROW, S.J.; VAIL, D.M. Tumors of skin and subcutaneous tissues. In: WITHROW \& MECEWEN'S. Small Animal Clinical Oncology. 4.ed. Missouri: Saunders. 2007.p.401-475.

YOON, J.S.; PARK, J. Immunohistochemical characterization of sebaceous epithelioma in two dogs. Iran. J. Vet. Res., v.17, p.134-136, 2016.

YUAN, D.; GOO, M.; YANG, H. et al. Adeno carcinoma of meibomian glands and moll in the eyelid of canine. J. Lif. Sci., v.18. p.414-417, 2008. 